\title{
The Effectiveness of Knowledge Management and Business Intelligence for Increasing Financial Performance: A Case Study of Petroleum Development Oman (PDO)
}

\author{
Nasra Hamed Al Siyabi \\ Dr. Nupur Goel
}

Middle East College
Middle East College

\begin{abstract}
The purpose of this study is to know about the effectiveness of integrating knowledge management and business intelligence for increasing the financial performance of Petroleum Development Oman Company. Based on the impact of this integration to increase the organization's performance, the data have been collected through primary and secondary sources. The main objective of this study is the integration between knowledge management and business intelligence and its effect on the financial performance of the company. In this research, two methods were discussed as direct influence and indirect influence. In the direct influence method, the company will use information that is generated by the process of knowledge management system and prepare the reports through business intelligence system for the company's financial plans and activities. Afterwards, the company can make appropriate financial decision to improve and develop the current financial plan and strategies. Another way is the indirect influence of the integration through focus on intellectual capital and human resources development through education and training, enhancing innovation, and using their capacities and skills in work. However, both influences contribute to increase efficiency, productivity, sales, profits, and reduced cost. Thus, improving the company's performance and its financial performance, which contributes to making sustainable the company in its business field market and maintains its competitive advantage
\end{abstract}

\section{Introduction}

World is witnessing a new revolution based on integrating the knowledge management with technology. One of the best integration processes is integrating knowledge management with business intelligence. This integration was built by understanding the main concept of knowledge management and business intelligence Herschel (2013) then, determining the process of these two systems and assuming the benefits of its application on any field. Knowledge management emerged to manage the knowledge resource that people or organizations owned by expanding the scope of using them. In the field of business, knowledge management can be defined as an integrated systematic process that aims to manage knowledge assets owned by the organization. This was conceived in a study done by Najibeh Rostami (2014). It was stated in the study that knowledge management refers to a systematic and organizational specific framework to capture, acquire, organize, and communicate both tacit and explicit knowledge. Furthermore, the role of knowledge management is ensuring access to all knowledge resources when needed. Business intelligence is process focused on using technology as a fast and efficient way in making decisions (Jayakrishnan 2018). Business intelligence is defined as an integrated approach that includes techniques, applications, tools, and practices that allow to analyze the available information or knowledge to choose the right information or knowledge in making and improving decisions (Rouhani 2012). Business intelligence refers to computer-based techniques used in spotting, digging-out, and 


\section{Journal of Student Research}

2019: Fourth Middle East College Student Research Conference, Muscat, Sultanate of Oman

analyzing business data or information on making decision process (Elena 2011).Keeping in view the benefits of using knowledge management and business intelligence, we take Petroleum Development Oman (PDO) Company as a case study. We study how the integration of knowledge management and business intelligence impacts in increasing the company's financial performance based upon the impact of integrating the knowledge management with business intelligence on increasing the organization's performance. Financial performance is a measure term which is used to describe the public financial health of the organization including organization's assets and generating income and profits in a particular period. Financial performance measure is used in comparing part with the other organizations in the same field of business or industry. Furthermore, financial performance can be defined as an accounting summary that details a business organization's revenues, expenses, and net income. Three financial statements comprise the statement of financial performance, which are income statement, balance sheet, and cash flow statement. Petroleum Development Oman Company (PDO) is one of the largest Omani companies and one of the leading oil and gas exploration and production companies in the Sultanate of Oman. In addition, it is one of the most established Omani companies that focusses on promoting growth, innovation, and creating a value-added and sustainable environment for businesses. According to Danijela Jelenic (2011), knowledge is a very important resource that helps organizations around the world to thrive and improves their competitive value. Also, knowledge management is a vital strategic resource for modern business. Its main objectives are raising the level of skills in the performance of internal processes in institutions through education and continuous training. As per the study conducted by Mzwandile Shongwe (2016), the author presented a framework for the knowledge management life cycle by analyzing many of the knowledge life cycles. The framework designed includes five stages: Knowledge Transfer, Storage, Application, Creation, and Acquisition.

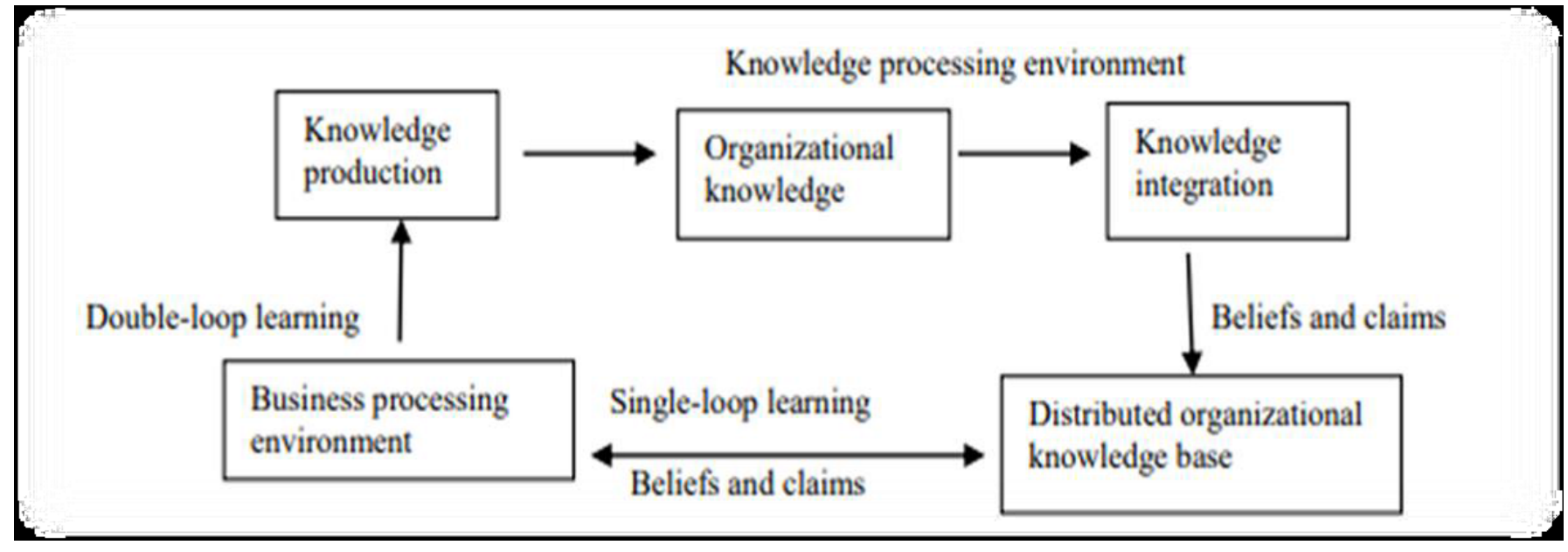

Figure 1. Knowledge Management Cycle Source: McElroy's Knowledge Management Cycle (Mohajan, 2016).

\section{Statement of the Problem}

Organizations are moving towards activating knowledge management system to develop their business. On the other hand, business intelligence comes as a technological part that interacts positively with knowledge management on organizations. The interaction of knowledge management and business intelligence ensures that organizations are effectively improving their performance and contribute to business culture in the organization (Choughri 2018). The risks of this interaction shown in case that the organization does not make appropriate strategy to take advantage of it. Creating successful strategies for using knowledge management and business intelligence is a wide-ranging guarantee. That ensures improving an organization's performance and maintaining competition in the same field of business or industry. However, this research seeks to determine and study the effects of merge knowledge management with business intelligence on financial performance based on the effects of this merge on organization's performance. We take Petroleum Development Oman Company as case study to study how the integrating of knowledge 
management with business intelligence effects the organization's performance and how it leads to increasing the financial performance.

The importance of this research is to show the effectiveness and impact of integrating knowledge management with business intelligence on financial performance. The integration of knowledge management with business intelligence leads to developing the intellectual capital. So, this project helps to study how intellectual capital leads to develop and increase the organization's capital, which leads to increase the financial performance.

\section{Objectives of the study}

The main objective of the study is to find the effectiveness of knowledge management and business intelligence for increasing financial performance in Petroleum development Oman.

\section{Research Methodology}

The adopted research methodology in this research is a mixed methods research. The mixed methods research includes both quantitative and qualitative approaches. The main propose of using mixed methods is the project idea itself, where it needs to collect quantitative and qualitative information to get more appropriate results.

\section{Data Collection}

Data was gathered through primary and secondary sources. The primary sources were questionnaires and interviews. The secondary sources included literature reviews of books journals, and websites.

\section{Population of the study}

PDO Company was selected for this study because it gradually started implementing knowledge management and business intelligence. The survey of this study included some of the company's directorates such as the Directorate of Human Resources, Financial Directorate, Planning Directorate, and IT Directorate.

\section{Sample Size}

The sample size of this research project was determined systematically as forty- seven persons, where forty persons of this sample were the employees of the target company's directorates and the other seven persons were the researchers and those who were interested in the field of knowledge management, business intelligence, and accounting and finance. However only 35 employees responded during the collection of data.

\section{Data Analysis and Discussion}

\section{Questionnaire results}

The questionnaire was designed to find answers to some research questions of this study. For example, how the integration between knowledge management and business intelligence impact on the organization's performance and financial performance? And, how is PDO Company increasing its financial profit after introducing the integration of Knowledge Management and Business Intelligence. The main questionnaire results are shown as follows: 


\section{Journal of Student Research}

2019: Fourth Middle East College Student Research Conference, Muscat, Sultanate of Oman

1. Employees familiarity with the knowledge and business intelligence management systems: The questionnaire included a diverse number of participants in terms of gender, qualification, and the number of experience years. Furthermore, it included the extent of their knowledge about the two systems. The analysis concluded that the participants' knowledge in the knowledge management system and business intelligence system varied between the preliminary, intermediate, and advanced knowledge. This disparity reflected that there was a clear desire from the company to develop the expertise of its employees in these two systems and keep the two systems available for all the employees.

2. Knowledge management system effectiveness in PDO Company: PDO Company has been implementing the knowledge management system for more than two years and the company follows some policies and strategies to implement the system according to its requirements and objectives. The analysis of the questionnaire showed that the effectiveness of implementing a knowledge management system within the company was measured by many effects such as promoting learning, sharing knowledge, and encouraging teamwork and innovation. Also, the system contributes in improving customer service and the problemsolving process by using the appropriate information resulting from the knowledge management process.

3. The effectiveness of the business intelligence system in PDO Company: PDO Company started applying business intelligence system prior to implementing the knowledge management system and the company followed systematic policies and strategies for applying this system according to the company requirements and objectives. The analysis of the questionnaire showed that the effectiveness of implementing business intelligence system within the company measured through the system effects. For example, it accelerated the decision-making process, it helped in preparing reports process and the process of monitoring and analysis of the company's overall situation according to its objectives. In addition, it promoted the use of knowledge in operational and managerial processes and developed corporate strategies such as developing and improving customer service strategies.

4. Effectiveness of integrating knowledge management system and business intelligence system on organizational performance and financial performance: The integration of knowledge management system and business intelligence system has many benefits such as improving data processing mechanism by making it more accurate and accessible by accessing useful information is available when needed. It also improves the decision-making process and prepares reports by providing the appropriate information to the right person at the right time to make the appropriate and right decision. Also, it develops and improves the company's goals and strategic plans. On other hand, integrating knowledge management with business intelligence has benefits on financial performance through focusing on intellectual capital and staff development or using the appropriate information and monitoring the work and the overall situation of the company to improve financial decisions.

Accordingly, we can conclude that there are positive impacts for integrating knowledge management systems with business intelligence on the organization's performance which directly effects its financial performance. This integration has direct influence and indirect influence on financial performance. The direct influence is coming through using the two systems to improve and develop financial decisions and plans, by using the useful information generated by the process of knowledge management system. It prepares reports and uses the records of the business intelligence system for the company's plans, actions, and activities. Then it makes appropriate financial decisions or improves and develops the current financial plans and strategies. On the other hand, the indirect influence of the integration is coming through focus on intellectual capital and the human resources development through education and training, enhancing innovation and using their capacities and skills in work. However, both influences contribute to increased efficiency, productivity, sales, profits, and reduced cost. Thus improving the company's performance and its financial performance, which contributes to sustainable the company in its business field market and maintains its competitive advantage. 


\section{Interview results}

The interviews were designed to elicit knowledge about the impact of integrating knowledge management and business intelligence on the organizations and financial performance. The interview answers resulted that the integration of knowledge management and business intelligence contributes to creating an integrated process that integrates the knowledge management process with the business intelligence system process. This process effectively effects on the company's performance and its financial performance. Financial performance is a measure for the general financial health of the company. The integration of knowledge management and business intelligence impact on financial performance through their influence on intellectual capital. The development of intellectual capital contributes to increasing the level of productivity and efficiency. Thus increase the level of sales and profits and reduce the level of costs. Otherwise, developing and improving financial strategies and decisions by using the right knowledge at the right time to make the right decisions. Which leads to increased levels of productivity, sales, and profits.

\section{Secondary Sources results}

The aim of using secondary sources was to support the results of primary sources. The most important secondary sources used in this research are books, e-books, literature, electronic journals, and Websites. Moreover, these secondary sources were used to answer some research questions as following:

1. Defined knowledge management on the business field and its working mechanism: Knowledge management is an approach that promotes to follow an integral method for determining, capturing, evaluating, restoring and sharing the organization's information assets. These assets present like databases, documents, policies, procedures, expertise, individual abilities, and skills. Moreover, knowledge management life cycle aims to process the available data and it includes five stages: knowledge creating, sharing, structuring, using, and auditing.

2. Defined business intelligence on the business field and its working mechanism: Business intelligence is a wide field of systems, applications, and techniques used to collect, store, analyze and provide information to improve the quality of business process modeling. Business intelligence focuses on providing the right information to the right people at the right time. However, the process of business intelligence systems is divided into three main stages. First stage defined the organization's capabilities, objectives, and requirements to define the goals of using the business intelligence system. In the second stage, analyzing data stored in transaction systems, and processing these data to keep it ready for usage. In the final stage, using the processed data in decision-making processes, reports, strategies, etc.

3. What is the integration between knowledge management and business intelligence? The integration between knowledge management and business intelligence is the result for the complementary relationship between them. Knowledge management generates usable knowledge through processing the available knowledge and information, while business intelligence introduces knowledge into business management and decision-making processes.

4. How the integration between knowledge management and business intelligence impact on the organization's performance? The integration of knowledge management system and business intelligence system has a positive impact on organizations performance through using the generated knowledge from the knowledge management system in the operations of the business intelligence system. The result of this integration generates a clear organizational structure, focusing on the organization requirements, and establishing specific objectives. Which for example leads to improving customer service, developing production processes, developing or changing strategies and supporting decision-making. 
Thus, it increases organizational performance in all aspects.

\section{Conclusion}

This study was purposed to study the effectiveness of integrating knowledge management with business intelligence on increasing financial performance of Petroleum Development Oman Company. On the basis of data analysis, the study concluded that the integration between knowledge and business intelligence effected positively on the organization's performance, which improved financial performance. There were direct and indirect impacts. The direct impact of applying the integration between knowledge management system and business intelligence system improved and developed financial decisions and plans. Further, the indirect impact of the integration of these two systems helped in developing intellectual capital and the development of human resources.

\section{Acknowledgements}

I send thanks letter to all those involved in the success of this project. A golden thanks letter to the immediate supervisor Dr. Nupur Goel for her valuable time for explaining, supporting and simplifying the research idea and requirements.

\section{References}

Cebotarean Elena (2011) "Business intelligence". Journal of Knowledge Management, Economics and Information Technology, 1 (2).

Danijela Jelenic (2011) "The Importance of Knowledge Management in Organizations - With Emphasis on the Balanced Scorecard Learning and Growth Perspective". Management, Knowledge and Learning International Conference, pp 33-43.

Haradhan Mohajan (2016) “A Comprehensive Analysis of Knowledge Management Cycles”. Journal of Environmental Treatment Techniques, pp.184-200.

Haradhan Mohajan (2017) 'The Roles of Knowledge Management for the Development of Organizations'. Journal of Scientific Achievements, pp. 121-129.

Mailasan Jayakrishnan, Abdul Karim Mohamad, and Mokhtar Yusof (2018) "Integrating The Features Of Knowledge Management (KM) And Business Intelligence (BI) for Developing Organizational Performance Framework - A Diagnostics Dashboard". American Scientific Publishers pp. 1795-1799

Najibeh Rostam (2014) "Integration of Business Intelligence and Knowledge Management - A literature review". Journal of Intelligence Studies in Business pp.30-40.

Radwan Choughri (2018) "Integrating Business Intelligence and Knowledge Management to Influence Organizational Innovation Process". IOSR Journal of Business and Management pp. 82-86.

Richard T. Herschel (2013) "Knowledge management and business intelligence: the importance of integration" Journal of Knowledge Management pp. 45-55.

Saeed Rouhani (2012). "Review Study: Business Intelligence Concepts and Approaches." American Journal of Scientific Research, pp. 62-75. 